\title{
Habitar los durantes: procesos creativos en el estudio de reescrituras en la dramaturgia contemporánea
}

\author{
LETICIA PAZ SENA Universidad Nacional de Córdoba, Argentina \\ ORCID 0000-0002-4245-185X \\ letipazsena@unc.edu.ar
}

\section{Resumen}

Investigar la dramaturgia contemporánea implica abordar la complejidad de escribir en/para la escena. La dramaturgia es una práctica específicamente teatral en la que la palabra está involucrada con las materialidades y temporalidades de la escena. En este marco, el estudio puntual de las prácticas reescriturales añade otras complejidades: el gesto de volver a escribir lo que ya ha sido escrito es de apropiación y recontextualización, lo que lleva a cuestionarse qué es la escritura, qué es la autoría, qué es el tiempo. A la vez, las prácticas artísticas del presente asumen su carácter político en la preocupación por los modos de crear, lo que trae para la investigación la necesidad metodológica de atender a los procesos creativos y no solo a las obras como productos o resultados.

En este trabajo nos proponemos aproximarnos al proceso creativo de Edipo R. —obra teatral de Organización $Q$, estrenada en Córdoba en 2008 y dirigida por Luciano Delprato-y nos interesa entender esta reescritura de Edipo Rey, de Sófocles, como un devenir-menor, en términos de Deleuze y Guattari.

Palabras clave: artes escénicas / dramaturgia / reescritura / procesos creativos / devenir-menor

\section{Dwell the durings: creative process in the study of re-writings in contemporary dramaturgy}

\section{Abstract}

The study of contemporary dramaturgy involves the complexity of write in/for the scene. Considering dramaturgy as a specific theatral practice -it means it is involved with scene's materialness and temporalities-, research's challenges have to look over some concepts and methods. The study of re-writing practice in dramaturgy adds another complexity: writing what was already written is a way of appropriation and recontextualization. Therefore, we ought to ask what writing is, what authority is and what time is. At the same time, actual arts are political because of their ways of creation; as a consequence, to research actual arts we have to attend the creative process, not only the product or the result.

In the present work, we want to approximate to Edipo R.'s creative process Organización Q's theater play, showed at the first time in Córdoba in 2008 and directed by Luciano Delprato - and we are interested in think about this re-writing of Oedipus the King, by Sophocles, as a becoming-minor, in the words of Deleuze \& Guattari.

Key words: performing arts / dramaturgy / re-writing / creative process / becoming-minor

\section{Recibido: 28/2/2021. Aceptado: 12/3/2021}

Para citar este artículo: Paz Sena, L. (2021). Habitar los durantes: procesos creativos en el estudio de 


\section{La dramaturgia contemporánea y algunas invitaciones metodológicas para su abordaje}

En el comienzo de una compilación de ensayos sobre dramaturgia contemporánea titulada Repensar la dramaturgia —y que con su subtítulo resume en dos palabras la deriva actual de esta práctica artística: errancia y transformación—, José Sánchez señala: «la dramaturgia está más allá o más acá del texto, se resuelve siempre en el encuentro inestable de los elementos que componen la experiencia escénica» (2010:19-20). Asumir las preguntas sobre qué significa escribir en las artes escénicas y cómo concibe la dramaturgia las prácticas teatrales del presente es, en efecto, asumir esa inestabilidad propia de aquello que está sucediendo, no solo por la particularidad de estudiar el presente sino también, por la convergencia simultánea de lo heterogéneo: cuerpos, tiempos, sujetos, prácticas, marcas, desapariciones. Indagar la dramaturgia implica necesariamente reconocer como punto de partida, la enorme ampliación de este concepto (Pavis, 2016; Dubatti, 2008; Manzone, 2017) y su carácter específicamente teatral, lejos de suponer que escribir en teatro sea posible con total autonomía de la escena y en especial muy lejos de concebir esta última como una concreción del texto, en subordinación con él. En el teatro contemporáneo, las prácticas dramatúrgicas conforman una zona de complejas exploraciones creativas que ponen en cuestión la idea misma de escritura, ya que allí se integran diferentes modalidades, sujetos creadores, temporalidades y materialidades. Las particularidades compositivas de la escritura teatral la convierten en un movimiento recursivo entre diferentes instancias —relación entre dirección y actuación en los ensayos, trabajos de mesa, transformaciones dadas en la representación-. De aquí que sea posible acudir al pensamiento de Roland Barthes (2011, 1976) para entender la escritura como una tensión entre la práctica y el goce: la práctica de escribir es una zona de entrecruce entre la palabra y la acción, entre el lenguaje y el cuerpo, entre lo dicho y lo no dicho. Movilizada por una paradoja productiva, la escritura escénica es el gesto imposible de capturar lo que ya no está, la huella siempre borrosa de un movimiento, del aquí y ahora de la escena, de la irrepetibilidad del acontecimiento.

Es en ese sentido que resultan atinadas las reflexiones de Joseph Danan, quien lee en el término dramaturgia los sedimentos de dos de sus sentidos: el sentido 1, más cercano a la idea convencional de texto: «arte de la composición de las obras de teatro» (2012:13) y, el sentido 2, moderno: «movimiento de tránsito de las obras de teatro hasta llegar a la escena» (13). En razón de ese movimiento, en el que se cruzan palabra y cuerpo, una mirada que investigue la dramaturgia es convocada a pensar los procesos, los durante y los devenires de tal acto.

Estas particularidades de la escritura teatral son las que ponen de relieve las dramaturgias de escena (Argüello Pitt, 2016; Dubatti, 2008) y que se enfatizan al pensar en propuestas que se basan en el procedimiento de la reescritura de textos. La variedad terminológica con la que artistas e investigadorxs se refieren a dicho procedimiento dramatúrgico - hipertextualidad, versión libre, adaptación, traducción, puesta en versión, entre otros términos- señala la heterogeneidad de prácticas al interior de una lógica compositiva tan antigua como vigente: la recuperación y apropiación de textos del pasado. La noción de reescritura permite destacar que se trata de un procedimiento específico de escritura, una escritura de una lectura (Barthes, 2009) que supone una interpretación y un encuentro deliberado con un texto otro en donde la palabra ajena no es meramente citada, sino apropiada, vuelta común; al reescribirla, la palabra de otrx —recontextualizada, resignificada y reconocida como otra— deviene derecho más que propiedad privada. 
Cuando es un colectivo de hacedorxs el que interviene, la palabra ajena se pone en cuestión y la autoría en tanto autoridad. Siguiendo a Foucault (2010), la función-autor -el modo de circulación de ciertos discursos - asignada a los discursos artísticos actualmente relaciona artistas y obras en términos de propiedad. En las reescrituras contemporáneas, la escritura se ejerce a través de lo que Reinaldo Laddaga (2010) llama autorías complejas cuyo modo de transgredir las representaciones del autor como figura de propiedad y autoridad se consuma con la consideración de dramaturgias de actuación, la condición co-creadora de lxs espectadorxs, en síntesis, con la conformación de comunidades de escritura.

La reescritura, entonces, es un entramado de textualidades (el o los textos a reescribir, intertextos, otras textualidades que se disparan como asociaciones, el texto teatral que se está escribiendo con sus diversas materialidades), de autoralidades (las convocadas por la propia reescritura, las convocadas por la escena) y de temporalidades (las del proceso — ensayos, trabajos de escritorio, funciones, reestrenos-y también las de la historia que son evocadas). A partir de la reconstrucción de las cartografías de lectura y escritura de los diferentes materiales presentes en el proceso creativo de una reescritura sería posible identificar los modos singulares por los cuales lxs creadorxs realizan estos solapamientos y con los cuales habilitan formas, también particulares, en las que el pasado resuena en el presente. Ciertamente, las reescrituras ponen en tensión el vínculo con el tiempo. Por un lado, el pasado no ejerce autoridad, puesto que «toda tradición se percibe como contingente, contradictoria, revisable» (Laddaga, 2010:23). Por otro lado, hay una distancia ejercida sobre el presente. Giorgio Agamben (2011), al preguntarse quées lo contemporáneo, responde que es una suerte de gesto de inactualidad, de anacronismo: desde la certeza de pertenencia al tiempo presente, pero sin poder adecuarse a él, lo contemporáneo se distancia. No se trata de una nostalgia, es un alejamiento que posibilita, de hecho, percibir el tiempo en una relación de adherencia y desfase. La distancia deja interpelar al tiempo: allí se da el gesto anacrónico que propone la reescritura, al identificar qué hay de arcaico en el presente. Menciona Agamben que arcaico significa próximo al origen; en este caso, no se trata de apuntar cronológicamente un comienzo, sino de señalar cómo habita y se inscribe el devenir histórico en el presente. El modo de acceder al instante presente se hace bajo la forma de una arqueología que no busca retroceder a lo remoto, sino a aquello del presente que permanece no-vivido y se subsume en un origen imposible de alcanzar jamás. Lo contemporáneo pone atención al presente en tanto no-vivido en lo vivido, como quien vuelve a un tiempo en el que nunca estuvo. Las dramaturgias contemporáneas basadas en reescrituras, siguiendo el planteo de Agamben, están situadas en el momento de quiebre del tiempo y en ese punto hacen encontrar a las temporalidades. De esta forma, se ejerce una transformación, ya que las reescrituras leen la historia de manera inédita.

Ante todo lo dicho, se van delineando algunos desafíos metodológicos para la indagación de prácticas reescriturales en el marco de dramaturgias de escena que ya han atravesado una etapa de estreno público de las piezas teatrales. Por un lado, ¿qué elementos constituyen el corpus de investigación si la tarea dramatúrgica es transversal a todo el proceso creativo (ensayos, texto teatral —en algunos casos, incluso, publicados -, funciones, reestrenos)? Por otro lado, gran parte de la dramaturgia «no está»: por su carácter efímero, porque no ha sido registrada materialmente. ¿Cómo pensar esta práctica de escritura sin reducirla a una sola dimensión: el documento, la huella de la escritura, la huella de su gesto? 
Estas inquietudes no son nuevas en el ámbito de las investigaciones sobre performance. Tal como señalan Hang y Muñoz, la pregunta sobre lo efímero ha sido la pregunta por la naturaleza de las artes performáticas y dispara un desafío en sus estudios que amerita no ser pensado desde la carencia, sino desde su potencia: las potencialidades que abre sobre los modos de escribir, sobre la concepción del tiempo, sobre otras formas posibles de constituir archivos no materiales, no estáticos o no visibles. Así, lo efímero "ya no sería una carencia, sino precisamente su fuerza y un postulado alternativo en un mundo donde todo tiene que dejar una huella visible, monetizable y comercializable» (Hang y Muñoz, 2019:20-21).

Por lo tanto, la identificación de las prácticas reescriturales a través de la reconstrucción de los procesos creativos - lo que Almedia Salles (2015) llama enfoque retrospectivo en crítica genéti$c a-$ se basa en una serie de reconocimientos. En primer lugar, es necesario reconocer el carácter incompleto de la reconstrucción de un proceso creativo que no se siguió y potenciar su tratamiento como ejercicio de memoria. En segundo lugar, cabe reconocer la heterogeneidad de los materiales que permiten esa reconstrucción, en sus diferencias de cantidad, calidad y densidad: registros fotográficos, sonoros o audiovisuales de ensayos y puestas en escena; entrevistas específicas a lxs creadorxs y sus discursos metapoéticos (ensayos escritos, entrevistas en la prensa, presentaciones públicas); documentos de proceso como cuadernos de dirección o versiones preliminares de los textos teatrales. Otro reconocimiento, prioritario, es la importancia de la producción de pensamiento por parte de lxs artistas, en su calidad de investigadorxs. Hay, en el campo teatral, experiencias que diluyen de modo interesante las distinciones tajantes entre teoría y práctica e incluso la división entre sujeto y objeto de la investigación. El conocimiento producido tanto por artistas-investigadorxs - quienes generan pensamiento a partir de su praxis creadora, de sus reflexiones sobre el arte o desde la docencia - como por investigadorxs-artistas — quienes, además de una carrera académica, desarrollan una carrera artística— (Dubatti, 2016:100) es valioso. Los saberes que se elaboran desde y sobre el teatro no se restringen a este ámbito, sino que significan una manera de comprender el mundo atravesada por la experiencia teatral. La relación entre práctica y pensamiento es recursiva y resulta interesante para la investigación de procesos creativos indagar esas mutuas implicaciones. Por último, es necesario también reconocer la frecuente situación de investigadorxs espectadorxs en el estudio de las artes escénicas del presente: la mirada de quien investiga está atravesada por la experiencia de expectación y, al reconstruir el proceso, como quien se asoma al revés de un bordado, amplía sus saberes en torno a dicha experiencia. Quien investiga se convierte en una suerte de espectadxr involucradx en el atrás/el antes/el durante de la puesta en escena que mira y los textos que lee. El punto de vista resulta una pura excepción, un artificio, y quizás allí resida su potencia: en el reconocimiento del estatuto de investigadxr-espectadxr que conoce a través de la experiencia, a través de un ejercicio colectivo de memoria y proponiendo una construcción del conocimiento compartida con lxs hacedorxs.

\section{Procesos creativos y devenires, reescrituras y minoridades}

Las dramaturgias contemporáneas demandan una correspondencia entre sus rasgos característicos y su abordaje: quien las estudie, más allá de encontrarse con una pieza teatral ya estrenada, se involucra en lo caótico, lo informe y lo inacabado del proceso creativo. El interés por reconstruir procesos reside en considerar que es en las dinámicas creativas y en las estrategias 
compositivas desplegadas donde acontecen las potencialidades políticas de las prácticas artísticas.

En esta línea, es posible entender el proceso creativo en tanto devenir, recuperando la reflexión que Deleuze y Guattari elaboran en torno a esta noción. El devenir se orienta hacia lo informe, hacia lo inacabado, desborda lo vivible y lo vivido y, más que alcanzar una forma, supone entrar en una zona de vecindad tal que implique la indistinción, la indiscernibilidad, la indiferenciación. Entender el proceso creativo como un devenir reivindica las instancias de inacabamiento, en las que priman la experimentación, el arrojo de hipótesis posibles y el tambaleo de certidumbres. Esa es, por cierto, la lógica de los ensayos en la creación escénica, en todos sus sentidos: intento, experimento, despliegue de ideas. El devenir, para Deleuze, interesa por aquello que sucede en el medio: «El medio no es una media, sino por el contrario un exceso. Es por el medio por donde las cosas crecen» (2003:82).

El pensamiento teatral francés ya recurrió a esta noción: Jean-Pierre Sarrazac (2013), posicionándose en el largo debate teatrológico en torno a la relación texto/escena, señala la "puestaen-juego» que supone la dinámica concurrente y polifónica entre todos los elementos de la representación —en la que el texto es un componente más, sin jerarquía-y delinea de este modo la noción de devenir escénico, en una clara referencia al pensamiento de Deleuze y Guattari:

Interrogarse hoy por el devenir escénico de un texto, por la multiplicidad de sus líneas de fuga, es tomar en consideración el grado de apertura de ese texto.

(...) el devenir escénico — reinvención permanente de la escena y del teatro por el texto— es lo que

religa más estrechamente, más íntimamente, este texto con su «Otro» exterior y extranjero. A saber: el

teatro, la escena. (Sarrazac, 2013:72)

El proceso dramatúrgico es un devenir: la escritura se agita sobre sí en un constante movimiento suscitado por el contacto con el acontecimiento incapturable, lo real de la escena, las materialidades de los cuerpos, la luz, el sonido. Esto significa, además de, como dijimos, desterrar posturas textocentristas que conciben la escena como una concreción del texto dramático, reconocer la dramaturgia como espacio de heterogeneidad. La escritura teatral, entonces, en esa reunión heterogénea e informe, deviene-común e inaugura, con ello, el despliegue de potencialidades inesperadas.

Las prácticas reescriturales instalan un vínculo con un texto otro y suman al devenir propio de la escritura teatral la complejidad de su tratamiento menor. Junto a Deleuze y Guattari (1978), podríamos considerar las reescrituras en tanto devenires-menores que entablan un vínculo crítico con dramaturgias mayores: obras consagradas de la tradición teatral occidental que suelen estar sometidas a regímenes de normalización. El tratamiento menor de estos textos, considerados clásicos, resulta un modo de hallar en ellos su «fuerza activa de minoridad» (Deleuze, 2003:83), esto es, desvíos posibles de los sistemas hegemónicos.

En Kafka. Por una literatura menor, Deleuze y Guattari trabajan la noción de devenir menor y despliegan una lectura de la obra de Kafka que pone en crisis ciertas interpretaciones fijas. La literatura kafkiana es una literatura menor porque funda devenires que son siempre menores, puesto que no se deviene Hombre, es decir, no se deviene dominante: se deviene mujer, animal o molécula en una permanente fuga que escapa a las formalizaciones. La minoridad no es una 
cuestión de reafirmación de jerarquías y posiciones, sino un trabajo de transformación que reencuentra las potencias propias del devenir. Lo menor señala, sí, la situación de exclusión de diferentes grupos ante una mayoría — masculina, blanca, heterosexual, adulta —, aunque dichos grupos sean muy numerosos (mujeres, niñxs, indígenas, por ejemplo) pero, a la vez y de modo más contundente, indica una potencialidad política. Así lo sintetiza Deleuze:

Devenir-minoritario es un objetivo y un objetivo que concierne a todo el mundo, ya que todo el mundo entra en ese objetivo y en este devenir, en la medida en que cada uno construye su variación en torno a la unidad de medida despótica, y escapa, por un costado o por el otro, al sistema de poder que hacía de él una parte de mayoría. (...) Minoría designa aquí la potencia de un devenir, mientras que mayoría señala el poder o la impotencia de un estado, de una situación. (2003:100-101)

En este sentido se entiende la función política específica del arte y la potencia de un tratamiento menor de lo mayor. Una literatura menor la ejerce en el plano de la lengua, desterritorializándola, así como articula lo individual en lo inmediatamente político y adquiere un valor colectivo y, por ello, revolucionario. Estas tres propiedades no definen algunas literaturas, sino «las condiciones revolucionarias de cualquier literatura en el seno de la llamada mayor (o establecida)» (Deleuze y Guattari, 1978:31).

Al pensar las prácticas reescriturales como procedimientos dramatúrgicos observamos un colectivo de artistas arrojadxs al encuentro con una otredad como puede ser la de una tragedia griega del siglo $\mathrm{V}$ a.C.: ceremoniales ajenos, pasados remotos, textos inconclusos, lenguas extranjeras, múltiples traducciones. Las reescrituras se convierten en el despliegue de protocolos de experiencia: experimentación menor de lo mayor. Podríamos pensar dos planos de este tratamiento menor: en primer lugar, el gesto mismo de la lectura que Deleuze y Guattari hacen de Kafka poniendo en crisis modelos canónicos de interpretar es el que las reescrituras entablan con los textos que desean reescribir; por tanto, lo que está en juego es una política de lectura. En segundo lugar, podríamos considerar el procedimiento dramatúrgico como la configuración de máquinas de expresión. En el devenir dramatúrgico, lxs artistas generan las condiciones textuales y escénicas - para esperar lo inesperado: no se sabe de antemano qué resultará del azar del encuentro. Para Deleuze y Guattari, las máquinas colectivas de expresión son aquellas que son capaces de «desorganizar sus propias formas y de desorganizar las formas de los contenidos para liberar nuevos contenidos» (1978:45), son aquellas que comienzan enunciando y los contenidos se ven arrastrados: «la expresión precede al contenido y lo arrastra» (63). La forma da el procedimiento: la forma reescritura, como máquina de escritura — deseo de escribir Sófocles, Eurípides, Shakespeare, como desea Pierre Menard, autor del Quijote: «la enunciación y el deseo son una y la misma cosa» (65)—, da el procedimiento, esto es, protocolos de experiencia, devenir menor de la Tragedia, de lo Clásico.

En su ensayo «Un manifiesto menos», Deleuze se detiene en Ricardo III o la horrible noche de un guerrero, de Carmelo Bene, una reescritura de Ricardo III, de Shakespeare. El filósofo entiende que entre los dos textos existe un vínculo crítico y le interesa identificar las operaciones del devenir menor que supone la pieza de Bene y que ponen en jaque a la representación. A través de la sustracción y la serie repetición-variación, Ricardo III, de Bene, deforma las figuras de poder en la tragedia shakesperiana y, como consecuencia, emergen problemáticas de minorías políticas 
antes desatendidas. Para Deleuze, el teatro de Bene no se trata de teatro dentro del teatro, ni de una parodia o una versión, sino de un teatro-experimentación que se ejerce desde el procedimiento de la sustracción, de la amputación de, por ejemplo, un personaje de la obra, lo que trae como consecuencia que, ante la ausencia no arbitraria de una parte, la obra bascule y gire sobre sí misma. De esta manera, los otros personajes adquieren desarrollo, se constituyen en escena, a partir de una serie permanente de metamorfosis y variaciones que hace proliferar lo inesperado. Esto quiere decir que, además de la supresión — la amputación o neutralización de los elementos de Poder-, la operación crítica se basa en la variación continua, propiedad creadora que experimenta con los elementos - el lenguaje o los personajes, por ejemplo — en todas sus variables y transformaciones en un lapso breve de tiempo, con lo cual el enunciado «no será más que la suma de sus propias variaciones, que lo hacen escapar de todo aparato de poder capaz de fijarlo y también esquivar toda constancia» (Deleuze, 2003:87). Las reescrituras someten al enunciado reescrito a su variación continua.

En las prácticas reescriturales, dijimos líneas arriba, vemos un amalgamiento de materialidades, textualidades y temporalidades. Considerarlas en su devenir implica entender el movimiento no como un tránsito desde un punto de partida hasta un punto de llegada. De hecho, muchas dramaturgias se encuentran con el texto a reescribir durante el proceso creativo, no todas las reescrituras nacen deliberadamente como proyectos, sino que devienen reescrituras durante los ensayos. Simultáneamente, hay propuestas que se conciben como reescrituras y luego el proceso deriva en trabajos de otro orden, donde el texto que había decidido reescribirse funciona como resonancia. Considerar las reescrituras en su devenir supone atender aquello que sucede en el medio, donde todo crece. El devenir habilita una reconfiguración de las temporalidades:

el medio no significa de ninguna manera estar en su tiempo, ser de su tiempo, ser histórico, al contrario. Es la vía por la cual los tiempos más diferentes se comunican. No es ni lo histórico, ni lo eterno, sino lo intempestivo. Y esto es justamente un autor menor: sin futuro ni pasado, no tiene más que un devenir, un medio, por el cual él mismo se comunica con otros tiempos, otros espacios. (Deleuze, 2003:82)

Ese contacto anacrónico con otros tiempos remotos y espacios distantes hace emerger vigencias inesperadas, menores y, por tanto, revolucionarias. En un tratamiento mayor, un pensamiento se vuelve una doctrina, una manera de vivir resulta una cultura, un acontecimiento resulta la Historia, un autor se convierte en Autor, con lo cual, con la pretensión del reconocimiento y la admiración, el resultado es la normalización. En el tratamiento menor, se busca «desprender devenires contra la Historia, vidas contra la cultura, pensamientos contra la doctrina, favores o desprecios contra el dogma» (Deleuze, 2003:83): un autor menor, en el medio, se comunica con otros tiempos y espacios de manera intempestiva y posibilita el reencuentro con las potencialidades de devenir.

Todxs, en relación con el hecho mayoritario, somos potencialmente minoritarixs si ejercemos algún tipo de desvío del modelo de poder. La práctica reescritural de la dramaturgia contemporánea se compromete con las potencialidades del devenir menor, al relacionarse con el texto a reescribir desde el movimiento, dado que lo despliega, lo transforma en sus relaciones de variación para esperar lo inesperado. 


\section{Habitar los durantes: sobre el proceso creativo de Edipo $R$. y su devenir-menor}

Edipo R. ${ }^{2}$ es una reescritura de Edipo Rey, de Sófocles, a cargo del grupo Organización Q, dirigida por Luciano Delprato y estrenada en 2008 en la sala de teatro independiente DocumentA/ Escénicas de la ciudad de Córdoba. Durante 2007, Carolina Cismondi ${ }^{3}$ —actriz, investigadora y docente de la Facultad de Artes de la Universidad Nacional de Córdoba- acompañó el proceso creativo como parte de sus investigaciones enmarcadas en la crítica de procesos desde una perspectiva genética y finalmente se involucró como asistente de dirección. Sus aportes (Cismondi, 2011; Cismondi y Sequeira, 2008) resultan valiosos para la tarea de estudiar el proceso compositivo de la dramaturgia de Edipo R. en tanto devenir y nos permiten, aunque en diferido, habitar el durante de la escritura. Entre sus insumos de investigación encontramos una entrevista realizada al director un año antes del estreno de la puesta: se trata de un momento informe del proceso, indefinido, de gestación prolífica de materiales (sin todavía descartar ninguno), en otras palabras, un estar en el medio, un devenir.

Delprato menciona que el encuentro con Edipo tiene lugar en el puro azar del ensayo, en el marco de una improvisación, de forma accidental. En ese sentido, el proceso no inicia como un proyecto reescritural, el deseo de encontrarse como grupo y de experimentar con el teatro de objetos — como marca identitaria de la estética de Organización Q, cuyos integrantes provienen de las artes plásticas - deviene en reescritura de Edipo Rey, de Sófocles, por accidente. Para Delprato, esta aparición es al mismo tiempo lo más inesperado y lo más coherente con el proceso: los muñecos, cuya manipulación venían experimentando en los ensayos, tienen para el director una afinidad con los arquetipos que conforman los héroes trágicos: carentes de subjetividad, vacíos de identidad, pueden ser llenados con aquello que lxs espectadorxs depositen en ellxs. Esta emergencia de la figura de Edipo resulta, para Delprato, una «fatalidad creativa», un azar del que responsabilizarse, un mundo imaginario del que hacerse cargo: «el azar no es menos nuestro que las cosas premeditadas» (Delprato, comunicación personal con Cismondi, 8 de junio de 2007).

El devenir de esa responsabilidad lleva a un compromiso con la fuerza gravitatoria que supone Edipo y un dejarse llevar hacia la lectura de la tragedia de Sófocles. En su rol de director, Delprato propone involucrarse magnéticamente con el mundo que se abre y esto genera entusiasmo e interés en el grupo, el proceso comienza a desplegar asociaciones textuales y culturales.

En simultáneo, el devenir dramatúrgico se ramifica. Por un lado, despierta el interés de estudiar la tragedia como sistema y trabajarla como pauta dramatúrgica y escénica. En tanto forma teatral ya inexistente, Delprato sugiere atender lo que ya no está. En el teatro occidental moderno se conservan la fábula, los personajes, lo dialógico. Lo que ya no está es el coro y esta ausencia se convierte en una inquietud formal: ¿cómo podría plantearse hoy el funcionamiento escénico y poético de un coro? La pregunta resuena en la operatoria misma de los integrantes de Organización Q como colectivo de manipuladores de muñecos. Se comienzan a ensayar metodologías para resolver estética y técnicamente el coro, el cual pasa a ser el centro del proceso: «si encontramos el coro vamos a encontrar a Edipo y vamos a poder tomar una decisión formal», allí reside lo específico de la tragedia y, en definitiva, la clave reescritural. Por otro lado, una segunda ramificación involucra una figura dentro del colectivo de creadorxs: la dramaturgista. En la tradición teatral alemana, se reconoce este rol como quien, no estando a cargo de la dirección ni de la autoría dramática, asiste en el proceso brindando lecturas, estudios específicos, material teórico y asociaciones textuales potentes para el proceso. Delprato solicita la colaboración de 
Daniela Martín — directora teatral, investigadora y docente — en esta tarea, que supone una asistencia para involucrarse con el mundo cultural que se abre. Dado que las vigencias de lo trágico son temas de interés tanto académicos como creativos para Martín — coincidentemente estrena en 2007 Griegos, una reescritura de Agamenón, de Esquilo-, ella se involucra con el proceso y comienza a asistir a ensayos, con la tarea de buscar «las resonancias históricas, sociales, filosóficas, estéticas que tiene el material que se está desarrollando. Trabajando con un material que tiene semejante resonancia cultural me parece que esa figura es prácticamente indispensable» (Delprato, 2007).

En el devenir del proceso, Delprato refiere permanentemente al vínculo que establece con los actores como una propuesta de colisión con los muñecos y con el texto trágico. Para la dramaturgia, su interés por la generación de materiales compositivos por parte de los actores es central, ya que considera que la potencia específica de lo actoral es ser un "pensamiento en acto» que descentra la mirada racional sobre el acontecimiento para privilegiar el cuerpo: «El trabajo del actor es en escena, todas las experiencias son enriquecedoras para el actor pero en tanto y en cuanto pueda reconocer las marcas que eso deja en su cuerpo y poner a disposición del espectáculo esas cicatrices» (Delprato, 2007). Las cicatrices funcionan como inscripciones dramatúrgicas con las que se atraviesa el devenir de la escritura.

Esta entrevista, en el medio del proceso, en el durante de la creación —el exceso propio del devenir, para Deleuze - es interesante leerla como un laboratorio de pensamiento en simultáneo al hacer creativo. Delprato define sus propios procesos como una espera de lo no previsto, una apertura a lo que se desconoce, el desafío de construir algo con lo que no se controla y con lo que todavía no se sabe qué es. Entendiendo al teatro como una forma de reflexionar sobre el mundo, Delprato se propone ampliar su mirada al tamaño del mundo, para lo cual demanda «procesos que estén siempre en un borde entrópico, a punto de no existir (...) en ese borde, en esa máxima tensión entre pulsión de vida y pulsión de muerte, aparece lo que no controlo, en el accidente» (Delprato, 2007).

Según Cismondi, desde la crítica en proceso de Edipo R. es posible observar «la relación indisociable entre los modos de trabajo y los resultados escénicos, donde el ensayo se vuelve un campo de experimentación constante» (2011:21). De este modo, la lógica del devenir que tiñe el proceso dramatúrgico de Edipo R. puede pensarse también puntualmente en el procedimiento reescritural, esto es, en su tratamiento menor de Sófocles.

En principio advertimos que lxs creadorxs ponen en funcionamiento una máquina de expresión signada por el interés de indagar las lógicas teatrales del bunraku, teatro de muñecos japonés. Esta máquina reasigna los componentes de la tragedia clásica occidental a una forma otra que la disloca y descentra. Pero, a la vez, la propia dinámica de la manipulación se pone en juego: es la búsqueda formal —el interés por la forma teatro de objetos— la que activa el universo semántico abierto por Edipo Rey: lo que está en crisis es el poder, ¿quién manipula a quién? Los manipuladores brindan sus voces y cuerpos para animar a los muñecos pero por momentos son estos los que se imponen sobre la corporalidad de los actores. La forma arrastra el contenido.

Por otra parte, el devenir menor también opera en la configuración espacial y escenográfica de la puesta. Edipo R. podría pensarse, como proponen Cismondi y Sequeira (2008), como una tragedia de cámara: el espacio escénico es pequeño, hay un despojo de elementos, los héroes trágicos 
devienen muñecos de madera, como una invitación a mirar microscópicamente los debates políticos que allí se suceden. Incluso el muñeco de Edipo dispone de dos muñecos, uno más pequeño que, paradójicamente, aunque parezca restringido al ámbito íntimo, aumenta la lupa sobre el carácter público de todo conflicto privado.

Los devenires menores de Edipo R. también conforman sus operaciones críticas a través de la variación continua. El proceso de reescritura involucró horas de lectura atenta de traducciones, de reflexión y elección minuciosa de las palabras para que estas resuenen, anacrónicas, plenamente vigentes en el presente. Hay una primera operación sobre la superficie: la incorporación de frases hechas, de referencias históricas de la Argentina contemporánea, desvíos que hacen vibrar los acontecimientos remotos en el ahora. Otra operación consiste en la apropiación y puesta en funcionamiento de frases prácticamente extraídas del texto de Sófocles, solo con variantes en el léxico. Es el caso de una referencia metateatral del coro en la estrofa II del estásimo II: «ipara qué voy a hacer coros rituales?» (Sófocles, 2016:119) que en Edipo R. persigue el mismo funcionamiento crítico: «Para qué mierda estamos todos juntos en esta sala de teatro» (Organización Q, 2008:42). Seguir de forma rigurosa la estructura de la tragedia clásica griega y poner a funcionar algunos pasajes en la reescritura supone someter al texto reescrito a su variación continua, por repetición y transformación, en un gesto que, más que de apropiación, podría ser de expropiación.

En este trabajo nos propusimos aproximarnos a un imposible que consideramos potente: habitar retrospectivamente el durante de un proceso creativo, volver a morar, desde la mirada de la investigación, en el territorio informe de un devenir. Las prácticas reescriturales de la dramaturgia contemporánea, entendidas como devenires menores, convocan preguntas sobre la escritura, sobre el tiempo y sobre la autoría y, en el ejercicio de la interrogación, hacen vibrar toda monumentalización para hacer emerger lo antes desatendido, lo inesperado. Los textos clásicos no son reescritos con un afán consagratorio, sino por reivindicación de la experimentación con superposiciones de temporalidades en pos de pensarnos en el presente.

¿Qué vuelve clásico a un clásico? Una respuesta posible es su capacidad para, a la manera del mito, suspender el flujo lineal del tiempo y permitirle que se pliegue sobre sí mismo, convenciéndonos de la idea de que los siglos no nos separan de Sófocles, sino que nos unen a él. (...)

Los clásicos son clásicos porque pertenecen a todas las épocas y a ninguna. Se vuelve necesaria una operación anticlásica para poder ponerlos en escena, para anclar estos navíos y sustraerlos por unos minutos de las corrientes transhistóricas (...) Son las aguas de un río que corre eternamente, pero que finalmente refleja en su superficie la imagen fija del presente. ¿Cuál es esta imagen, la que me devuelven las superficies bruñidas del Edipo a mí, sujeto de una pequeña comunidad tercermundista hoy en Sudamérica? Y, si verdaderamente es un clásico, ¿cuáles son los elementos de esta imagen que hacen que yo me parezca al resto de la humanidad? (Delprato, 2008:8 y 10)

Las prácticas reescriturales, en su tratamiento menor, abren a espesuras conceptuales y culturales que ameritan ser recorridas. Se proponen como un trabajo de fricción con un material que conforma una otredad. En ese cruce friccionado, en esa colisión, en ese azar sería interesante ver inauguradas miradas más abiertas sobre el mundo, siempre en devenir. 


\section{Notas}

1 El devenir es la operatoria misma del deseo: no implica reproducción o imitación de aquello en lo que se deviene, sino afectación recíproca: «Devenir nunca es imitar, ni hacer como, ni adaptarse a un modelo, ya sea el de la justicia o el de la verdad. Nunca hay un término del que se parta, ni al que se llegue o deba llegarse. Ni tampoco dos términos que se intercambien. (...) Los devenires no son fenómenos de imitación ni de asimilación, son fenómenos de doble captura (...). La abeja y la orquídea nos dan el ejemplo. La orquídea aparenta formar una imagen de abeja, pero de hecho hay un devenir abeja de la orquídea, un devenir-orquídea de la abeja, una doble captura, puesto que "lo que" cada una deviene cambia tanto como "el que" deviene» (Deleuze, 1997:6). En ese sentido, las reescrituras no se vinculan con el texto reescrito en términos ejemplares o monumentales, buscando consagrarse a través de un modelo, sino que buscan ese espacio indiscernible de afectación mutua.

2 Ficha técnica de Edipo R., de Organización Q. En escena: Xavier Del Barco, Luciano Delprato (Daniel Delprato en el estreno), Leopoldo Cáceres, Marcos Cáceres y Rafael Rodríguez. Diseño escenográfico: Luciano Delprato y Rafael Rodríguez. Diseño Iluminación: Rafael Rodríguez. Diseño sonoro y música original: Pablo Cécere. Asistencia de dirección puesta original: Carolina Cismondi. Producción general y asistencia de dirección re-estreno: María Paula Del Prato. Fotografías: Melina Passadore. Dramaturgia, puesta en escena y dirección: Luciano Delprato.

3 Agradecemos a Carolina Cismondi su generosidad al compartir sus insumos de investigación (registros audiovisuales de puestas y ensayos).

\section{Referencias}

Agamben, G. (2011). Desnudez. Buenos Aires: Adriana Hidalgo.

Almeida Salles, C. (2015). Crítica de los procesos creativos. En Revista ARTilugio, 1(1). https://revistas.unc. edu.ar/index.php/ART/article/view/12255

Argüiello Pitt, C. (2016). Dramaturgia de la dirección de escena. México: Paso de Gato.

Barthes, R. (1976). ¿Qué es la escritura? El grado cero de la escritura. Nuevos ensayos críticos (17-26). Buenos Aires: Siglo XXI.

Barthes, R. (2009). El susurro del lenguaje. Más allá de la palabra y la escritura. Barcelona: Paidós.

Barthes, R. (2011). El placer del texto y Lección inaugural de la cátedra de Semiología Literaria del Collège de France. Buenos Aires: Siglo XXI.

Cismondi, C. y Sequeira, J. (2008). Griegos y Edipo R., dos interpelaciones al teatro contemporáneo desde la ética griega. telondefondo. Revista de teoría y crítica teatral, (8), 1-26. http://revistascientificas.filo.uba.ar/ index.php/telondefondo/article/view/9392

Cismondi, C. (2011). Variaciones teatrales de crítica genética. Manuscrítica. Revista de Crítica Genética, (21), 1360. Associação dos Pesquisadores em Crítica Genética (APCG) e Pós-graduação em Estudos Linguísticos, Literários e Tradutológicos em Francês, Universidade de São Paulo. http://www.revistas.fflch.usp.br/ manuscritica/article/view/1138/1037

Danan, J. (2012). Qué es la dramaturgia y otros ensayos. México: Paso de Gato.

Deleuze, G. (2003). Un manifiesto menos. En Bene, C. y Deleuze, G. Superposiciones (75-102). Buenos Aires: Artes del Sur.

Deleuze, G. y Guattari, F. (1978). Kakfa. Por una literatura menor. México: Era.

Deleuze, G. y Parnet, C. (1997). Diálogos. Valencia: Pre-Textos.

Delprato, L. (2007). Entrevista inédita realizada por Carolina Cismondi, Córdoba.

Delprato, L. (2008). Causas y efectos de Edipo Rey. Un destino de juguete. En AA. VV. Apuntes de escena (8-10). Córdoba: Ediciones DocumentA/Escénicas. 
Dubatti, J. (2008). Textos dramáticos y acontecimiento teatral. Cartografía teatral. Introducción al Teatro Comparado (135-171). Buenos Aires: Atuel.

Dubatti, J. (2016). El artista-investigador, el investigador-artista, el artista y el investigador asociados, el investigador participativo: filosofía de la praxis teatral. Una Filosofía del Teatro. El teatro de los muertos (97-129). Lima: Dirección de Investigaciones y Área de Ediciones de la Escuela Nacional Superior de Arte Dramático.

Foucault, M. (2010). ¿Qué es un autor? Córdoba: Ediciones literales/El Cuenco de Plata.

Hang, B. y Muñoz, A. (Comps.) (2019). El tiempo es lo único que tenemos. Buenos Aires: Caja Negra.

Laddaga, R. (2010). Estética de laboratorio. Estrategias de las artes del presente. Buenos Aires: Adriana Hidalgo.

Manzone, V. (2017). El cuerpo dramatúrgico. Estudios de Teoría Literaria. Revista digital: artes, letras y humanidades, 6(11), 133-146. https://fh.mdp.edu.ar/revistas/index.php/etl/article/view/1951

Organización Q (2008). Edipo R. Córdoba: inédito.

Pavis, P. (2016). Diccionario de la performancey del teatro contemporáneo. México: Paso de Gato.

Sánchez, J.A. (2010). Dramaturgia en el campo expandido. En AA. VV. Repensar la dramaturgia. Errancia y transformación /Rethinking dramaturgy. Errancy and transformation (19-37). Murcia: Centro Párraga y Centro de Documentación y Estudios Avanzados de Arte Contemporáneo (CENDEAC).

Sarrazac, J.P. (Dir.) (2013). Léxico del drama moderno y contemporáneo. México: Paso de Gato.

Sófocles (2016). Edipo Rey. Buenos Aires: Losada. Traducción de Ingberg, P. 